\title{
Анализ материалов для рабочего диэлектрика моноблочного многофункционального высоковольтного импульсного конденсатора
}

\author{
* В. И. Гунько, А. Я. Дмитришин, А. П. Малюшевская, С. О. Топоров \\ Институт импульсных процессов и технологий НАН Украинь, \\ 2. Николаев, 54018, Украина, ${ }^{*}$ e-mail: dphc@iipt.com.ua \\ Поступила в редакцию 30.09.2020 \\ После доработки 26.11.2020 \\ Принята к публикации 26.11.2020
}

\begin{abstract}
Проведен анализ диэлектрических материалов, которые могут быть применены в качестве рабочего диэлектрика моноблочного многофункционального высоковольтного импульсного конденсатора. В частности, рассмотрены свойства жидких диэлектриков, которые могут использоваться в качестве пропитывающего диэлектрика. Также исследованы свойства полипропиленовой пленки, рекомендованной для изготовления конденсаторов с высокой частотой следования зарядов-разрядов. Даны рекомендации по применению диэлектриков для диэлектрической системы моноблочного многофункционального высоковольтного импульсного конденсатора.
\end{abstract}

Ключевые слова: пленочный диэлектрик, диэлектрическая пропитывающая жидкость, высоковольтный импульсный конденсатор

УДК 621.319.4

https://doi.org/10.52577/eom.2021.57.2.54

\section{ВВЕДЕНИЕ}

В ряде случаев для проведения электрофизических исследований или реализации разрядноимпульсных технологий существует необходимость создания относительно невысоких рабочих напряжений при обеспечении высоких значений энергии в единичном импульсе. Традиционно это решается за счет применения одновременно нескольких высоковольтных импульсных конденсаторов, электрически соединенных между собой. Однако часто такой способ формирования накопителя электрической энергии приводит к нежелательному изменению параметров разрядного контура, например в части увеличения его индуктивности. Кроме того, при этом происходит увеличение массогабаритных показателей электротехнического устройства.

Существует и другой путь решения задачи создания современных исследовательских электротехнических комплексов с изменяемыми параметрами - формирование емкостного накопителя электрической энергии из одного высоковольтного импульсного конденсатора с высокой удельной запасаемой энергией, который позволяет варьировать параметрами разрядного импульса при одновременном изменении электрической емкости конденсатора и его рабочего напряжения.

Ранее ООО «Гириконд» (РФ) для указанных целей изготавливались высоковольтные импульсные конденсаторы серии К 42 И-1 [1], которые имеют четыре конструктивных исполнения с электрической емкостью от 10 до 50 мкФ при рабочем напряжении 2 кВ и 10 мкФ при рабочем напряжении 3 кВ. У этих конденсаторов относительно небольшие массогабаритные показатели, однако в их конструкции применена металлизированная бумага, что не позволяет использовать указанные конденсаторы в режимах с высокой частотой следования импульсов и с высокими значениями разрядного тока.

ЗАО «Русская технологическая группа» [2] создана серия высоковольтных импульсных конденсаторов типа КПИ в изоляционном корпусе на основе пленочной диэлектрической системы. При этом два номинала этих конденсаторов имеют изменяемую электрическую емкость за счет вынесения токовыводов четырех отдельных пакетов конденсаторных секций. Максимальная электрическая емкость этих конденсаторов составляет 160 мкФ при рабочем напряжении 6,3 кВ и частоте следования импульсов до 1 Гц. Также создана серия малоиндуктивных конденсаторов типа КПИМ с двумя парами токовыводов, максимальной электрической емкостью 80 мкФ при рабочем напряжении $5 \mathrm{\kappa B}$, частота следования импульсов этой серии конденсаторов ограничена величиной 1 Гц.

Международной компанией Vishay для силовой электроники создана серия конденсаторов типа ESTA [3] для реализации 
импульсных процессов - серия конденсаторов типа ДСМКР (с величинами номинальной электрической емкости от 50 до 20000 мкФ и рабочим напряжением от 900 до 4250 В) и типа EPR (с величинами номинальной электрической емкости от 2 нФ до 2 мкФ и рабочим напряжением от 3 до 1000 В). Однако частота следования импульсов для конденсаторов этих серий не превышает 0,1 Гц.

Цель данной работы - анализ материалов для рабочего диэлектрика, который будет использован при создании моноблочного многофункционального высоковольтного импульсного конденсатора, обладающего высокой удельной запасаемой энергией, допускающего эксплуатацию в режимах с высокой частотой следования импульсов (до 100 Гц) и амплитудами разрядного тока до 40 кА.

\section{ОБЗОР ЖИДКИХ ДИЭЛЕКТРИКОВ}

Создаваемый высоковольтный импульсный конденсатор предназначен для эксплуатации в режимах c высокой частотой следования импульсов, в связи с этим в качестве его рабочего диэлектрика однозначно должны быть применены неполярные электроизоляционные полимерные пленки, обладающие одновременно как малыми диэлектрическими потерями, так и высокой электрической прочностью [4]. Кроме того, обеспечение надежности конденсатора в условиях больших токовых нагрузок исключает применение в качестве его обкладок слоя металлизации, нанесенного на пленку.

Известно, что одним из способов повышения электрической прочности рабочего диэлектрика конденсатора является термовакуумная сушка и пропитка слоев полимерной пленки электроизоляционной жидкостью, правильный выбор которой обеспечивает длительную надежную работоспособность конденсатора в целом $[5,6]$. В Институте импульсных процессов и технологий (ИИПТ) ранее проводились экспериментальные исследования по выбору пропитывающих жидкостей для пленочного рабочего диэлектрика высоковольтных импульсных конденсаторов, критерием выбора являлась долговечность диэлектрической системы пленкажидкость [4, 7]. Было установлено, что для этих целей оптимально подходят маловязкие неполярные диэлектрические жидкости, обеспечивающие высокие значения как кратковременной, так и длительной электрической прочности пленочного диэлектрика.

В табл. 1 приведены характеристики маловязких неполярных диэлектрических жидкостей, широко применяемых в мировой практике для пропитки пленочной изоляции в современных высоковольтных устройствах.

Наиболее широкое применение в мире для пропитки пленочной изоляции нашли минеральные нефтяные масла [3]. При изготовлении высоковольтных импульсных конденсаторов на основе пленочных диэлектрических систем в ИИПТ НАН Украины и НИПКИ «Молния» НТУ «ХПИ» используются трансформаторные масла марок Т-1500 ДСТУ 982-80 и ГК ТУ 38-401-358-84, соответственно относящиеся к минеральным нефтяным маслам [4, 8-11]. Характеристики этих масел близки между собой, масла отличаются друг от друга только происхождением и способом очистки [12]. В европейских странах для пропитки пленочной изоляции высоковольтных устройств широкое применение нашли трансформаторные масла марок Nutro 10XN и Nutro 11GX производства фирмы NYNAS (Швеция), являющейся мировым лидером в производстве трансформаторных масел [13, 14]. Масла марок Nutro 10XN и Nutro $11 \mathrm{GX}$ являются аналогами украинских трансформаторных масел марок Т-1500 и ГК.

Обычный цвет трансформаторных масел соломенно-желтый, характеризующий глубину очистки масла, - чем светлее масло, тем больше глубина его очистки. Однако, как показал опыт производства высоковольтных импульсных конденсаторов в ИИПТ, пропитанных высокоочищенными конденсаторными нефтяными маслами, такие конденсаторы выходили из строя чаще, чем в случае их пропитки трансформаторными нефтяными маслами, имеющими меньшую глубину очистки. Трансформаторные нефтяные масла содержат более высокий процент природных антиокислителей и являются более стойкими к воздействию электрического поля [12].

Большими недостатками нефтяных масел являются нестабильность их свойств, связанная c происхождением (месторасположением нефтяной скважины), горючесть, относительно низкая газостойкость, низкая термоокислительная стабильность, к этому следует прибавить истощение нефтяных скважин, пригодных для производства электроизоляционных масел. Учитывая эти факторы, в настоящее время в мировой практике создания высоковольтного оборудования происходит вытеснение нефтяных масел синтетическими углеводородами [10].

При создании отдельных типов силовых конденсаторов на основе пленочных диэлектрических систем широкое применение нашли синтетические кремнийорганические жидкости. Это, например, силовые конденсаторы для подвижного электротранспорта угольных шахт, 
Таблица 1. Характеристики маловязких неполярных диэлектрических жидкостей

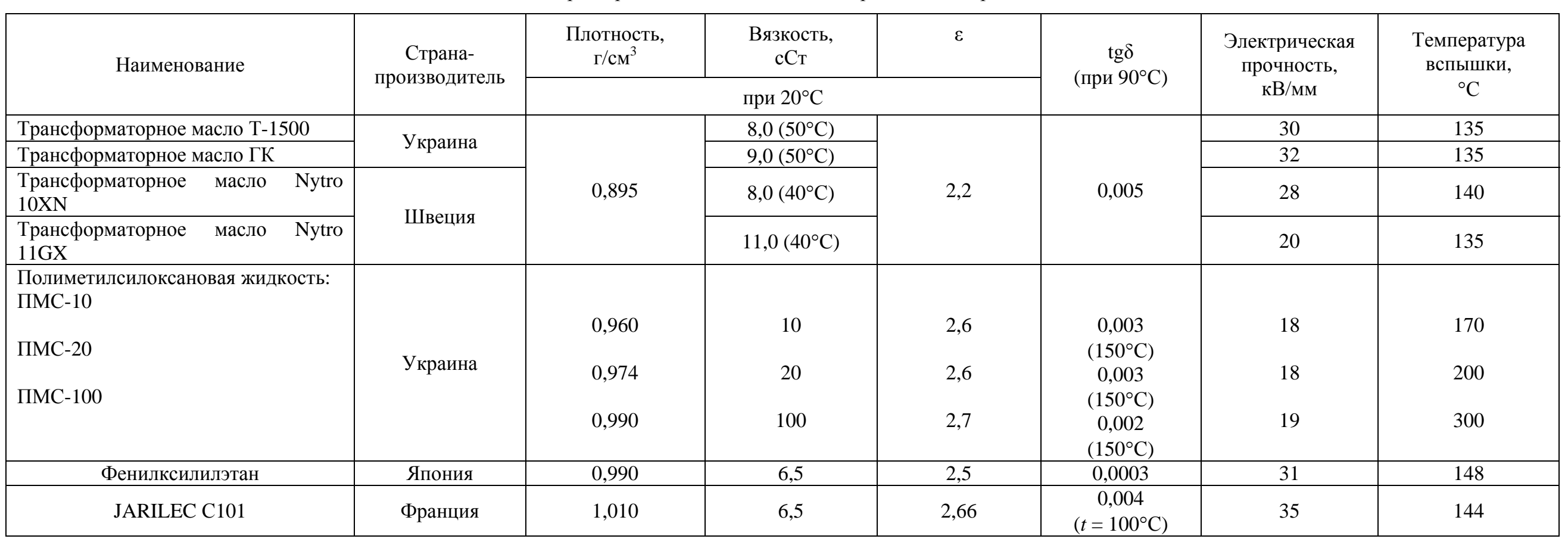


где к конденсаторам предъявляются высокие требования по пожаробезопасности. Также эти жидкости применяются для пропитки высоковольтных импульсных конденсаторов электрогидроимпульсных устройств для увеличения дебита нефтяных и газовых скважин, предназначенных для эксплуатации при повышенных до $100^{\circ} \mathrm{C}$ температурах окружающей среды $[15,16]$. В качестве пропитывающих жидкостей пленочного рабочего диэлектрика этих конденсаторов наиболее широкое применение получили полиметилсилоксановые кремнийорганические жидкости [8]. Эти жидкости нетоксичны, экологически безопасны, имеют высокую термоокислительную стабильность и эксплуатационную надежность. Вязкость полиметилсилоксановых жидкостей, в зависимости от молекулярной массы, находится в диапазоне от 1 до 1000 сСт, диапазон рабочих температур этих жидкостей от минус $50^{\circ} \mathrm{C}$ до плюс $200^{\circ} \mathrm{C}$ [17].

K недостаткам полиметилсилоксановых жидкостей следует отнести их гидрофобность, сравнительно низкую электрическую прочность и невысокую газостойкость, поэтому не рекомендуется их применять в высоковольтных импульсных конденсаторах, предназначенных для эксплуатации в режимах с высокой частотой следования импульсов [12].

В настоящее время в конструкциях силовых конденсаторов, работающих на промышленных частотах 50 Гц, 60 Гц и выше, вместо традиционных бумажного и комбинированного бумажно-пленочного рабочего диэлектрика стал применяться диэлектрик на основе полипропиленовой пленки. Применение пленочного диэлектрика в этих конденсаторах потребовало создания для них и новых пропитывающих жидкостей, таких как JARILEC C101 производства фирмы Arkema (Франция) и фенилксилилэтан производства фирмы Nippon Chemical Со (Япония) [15, 18-21].

Диэлектрическая жидкость JARILEC C101 представляет собой смесь 75\% монобензилтолуола и 25\% дибензилтолуола. Эта жидкость химически стабильна, имеет приемлемую электрическую прочность, малую вязкость, низкую температуру застывания, экологически совместима, относится к классу умеренно небезопасных веществ. Ранее в ИИПТ проводились экспериментальные исследования диэлектрических жидкостей для пропитки пленочных диэлектриков, и после работы с жидкостями на основе смеси моно- и дибензилтолуолов от рабочего персонала поступали жалобы на резкий запах жидкости и симптомы аллергии. Производитель JARILEC C101 признает тот факт, что жидкость имеет сильный резкий запах, который может негативно влиять на рабочий персонал. Фирмой Arkema была создана диэлектрическая жидкость JARILEC C101 D, являющаяся ароматизированным вариантом жидкости JARILEC C101 в части снижения интенсивности резкого запаха [21].

Более широкое применение по сравнению с диэлектрической жидкостью JARILEC C101 для пропитки пленочного рабочего диэлектрика на основе полипропиленовой пленки в силовых конденсаторах получил фенилксилилэтан синтетическая ароматическая жидкость ряда диарилалкана [22]. Например, Усть-Каменогорский конденсаторный завод (Казахстан) изготавливает ряд силовых конденсаторов на основе пленочного рабочего диэлектрика, пропитанного фенилксилилэтаном [23]. Фенилксилилэтан среди всех рассмотренных в работе диэлектрических жидкостей имеет наибольшую газостойкость, стойкость к воздействию частичных разрядов, экологически безопасен, относится также к классу умеренно небезопасных веществ.

При выборе диэлектрической системы высоковольтных импульсных конденсаторов в ИИПТ экспериментально исследовались диэлектрические системы на основе полипропиленовой, поликарбонатной и полиэтилентерефтолатной полимерных пленок [4]. В качестве жидких пропитывающих диэлектриков пленочных структур исследовались такие маловязкие неполярные диэлектрические жидкости, как фенилксилилэтан, трансформаторное масло типа Т-1500, полиметилсилоксановые жидкости типа ПМС-10, ПМС-20 и ПМС-100. Исследования показали, что тип пропитывающей жидкости оказывает большое влияние на долговечность пленочной диэлектрической системы высоковольтного импульсного конденсатора. Так, в одинаковых условиях и режимах испытаний образцы на основе полипропиленовой пленки с пропиткой фенилксилилэтаном характеризовались наибольшими значениями кратковременной и длительной электрической прочности.

Кроме того, в [24] приведены данные по экспериментальным исследованиям долговечности пленочных диэлектрических систем, где в качестве жидкого пропитывающего диэлектрика исследовались такие жидкости, как минеральные нефтяные масла, фенилксилилэтан, JARILEC C101 и Миксофлекс 1000 производства фирмы Prodelec (Франция). В результате этих исследований было установлено, что наибольшей долговечностью обладает диэлектрическая система на основе полипропиленовой пленки и фенилксилилэтана. 


\section{ИССЛЕДОВАНИЯ ПОЛИПРОПИЛЕНОВОЙ ПЛЕНКИ}

Таким образом, в качестве рабочего диэлектрика моноблочного многофункционального высоковольтного импульсного конденсатора выбрана диэлектрическая система на основе полипропиленовой пленки и фенилксилилэтана. Кроме того, в [6] рекомендовано для создания конденсаторов, эксплуатирующихся в режимах с высокими частотами следования импульсов, использовать именно полипропиленовую пленку, как обладающую одновременно наиболее высокой электрической прочностью и низкими диэлектрическими потерями.

Полипропиленовую диэлектрическую пленку изготавливают из изотактического полипропилена. Эта пленка обладает одновременно высокой электрической прочностью, малыми диэлектрическими потерями, дешевизной, и благодаря возможности модификации технологических возможностей ее производство широко налажено в мире [12]. В США полипропиленовая пленка выпускается под названием «пропатен», в Италии - «моплефан», в Великобритании «пропафилм Е», в Германии - «хостален», в Украине - «Тервакоски филм», в Японии «донбанд».

Свойства полипропиленовой пленки в большой степени зависят от способа еe получения - экструзией или выдуванием. При способе экструзии расплавленный полимер продавливается через щелевую фильеру на поверхность полированного охлаждаемого металлического барабана, с которого далее снимается остывшая пленка. При этом получается заготовка, толщина которой на порядок выше толщины готовой пленки. С целью уменьшения толщины заготовки и ориентации молекул пленки, для повышения еe механической и электрической прочности производится растягивание пленки при температуре ниже температуры выдавливания, но выше температуры стеклования. Растягивание заготовки пленки производят в двух направлениях, так называемое двуосное ориентирование, что позволяет избежать склонности одноосно вытянутой пленки к продольному растрескиванию. Способ выдувания отличается тем, что расплавленный полимер продавливается через кольцевую фильеру и раздувается в середине потоком горячего сжатого воздуха в заготовку в виде рукава, который затем разрезается и полученная плоская заготовка подвергается двуосному ориентированию. В табл. 2 приведены характеристики неориентированной и ориентированной полипропиленовой пленок [25].

Способом выдувания изготавливается более мягкая пленка и с большим разбросом по толщине, а способом экструзии - более тонкая, более твердая и с меньшим разбросом по толщине. В США применяется способ выдувания, в Италии, Франции, Украине и Германии - способ экструзии, в Японии применяются оба эти способа.

Поверхность пленки может иметь как природную, так и искусственно приданную одностороннюю или двустороннюю шероховатость. Наличие шероховатости на поверхности пленки позволяет обеспечить качественную пропитку пленочного диэлектрика высоковольтного импульсного конденсатора, а также облегчает процесс намотки конденсаторных секций, уменьшая слипание слоев пленки между собой. В табл. 3 приведены классы полипропиленовой пленки по шероховатости.

Рекомендованный температурный диапазон эксплуатации полипропиленовой пленки является достаточно широким и лежит в диапазоне от минус $60^{\circ} \mathrm{C}$ до плюс $100^{\circ} \mathrm{C}$.

Необходимо отметить, что электрофизические характеристики полипропиленовых пленок различных производителей незначительно различаются между собой. В ИИПТ были проведены экспериментальные сравнительные исследования шероховатой полипропиленовой пленки толщиной 10 мкм, $R_{a}=0,04$ мкм производства LTD Polimero da petrolio Со (Линьяно, Италия) и шероховатой полипропиленовой пленки толщиной 10 мкм, $R_{a}=0,36$ мкм производства ЗАО «Терихем» (Луцк, Украина), критерием оценки являлась величина кратковременной электрической прочности $E_{\text {пр }}$.

Кратковременная электрическая прочность определялась на 20 образцах (по пять электрических пробоев на образец) каждой пленки. Испытания пленок проводились согласно ГОСТ 6433.3-71 «Материалы электроизоляционные твердые. Методы определения электрической прочности» с помощью аппарата АИИ-70 ТУ 25-06-1769-76, а регистрация значения электрического напряжения пробоя $U_{\text {пр }}-$ с помощью киловольтметра электростатического С-196 ТУ 25-04-130-79. При расчете $E_{\text {пр }}$ по формуле $E_{\text {пр }}=U_{\text {пр }} / h_{\text {ср }}$ использовалось среднее значение толщины листа пленки $h_{\text {сp }}$, определенное с точностью до 0,5 мкм. Толщина образцов пленки для расчета $E_{\text {пр }}$ определялась согласно ГОСТ 17035-86 «Пластмассы. Методы определения толщины пленок и листов» за выборкой 10

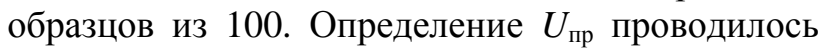
в электродной системе стержень-стержень, 
Таблица 2. Характеристики неориентированной и ориентированной полипропиленовых пленок

\begin{tabular}{|l|c|c|}
\hline \multicolumn{1}{|c|}{ Характеристика } & Неориентированная пленка & Ориентированная пленка \\
\hline $\begin{array}{l}\text { Разрывное усилие при вытягивании в продольном } \\
\text { направлении, МПа }\end{array}$ & 35 & 200 \\
\hline Относительное удлинение при разрыве, \% & 500 & 100 \\
\hline Температура крошения, ${ }^{\circ} \mathrm{C}$ & Плюс 8 & Меньше минус 40 \\
\hline Электрическая прочность, кВ/мм & 400 & 700 \\
\hline
\end{tabular}

Таблица 3. Классы полипропиленовой пленки по шероховатости

\begin{tabular}{|l|c|}
\hline Класс пленки & Среднеарифметическое отклонение профиля $R_{a}$, мкм \\
\hline Гладкая & $0,05-0,07$ \\
\hline Слабошероховатая & $0,10-0,15$ \\
\hline Шероховатая & $0,30-0,60$ \\
\hline
\end{tabular}

Таблица 4. Основные технические параметры и характеристики моноблочного многофункционального высоковольтного импульсного конденсатора

\begin{tabular}{|c|c|c|c|c|c|c|c|}
\hline $\begin{array}{c}\text { Наименование } \\
\text { параметров и } \\
\text { характеристик }\end{array}$ & \multicolumn{7}{|c|}{ Значение } \\
\hline Рабочее напряжение, кВ & \multicolumn{4}{|c|}{3} & \multicolumn{2}{|c|}{6} & 12 \\
\hline $\begin{array}{ll}\text { Номинальная емкость, } \\
\text { мкФ }\end{array}$ & 50 & 100 & 150 & 200 & 25 & 50 & 12 \\
\hline $\begin{array}{lc}\text { Средний } & \text { ожидаемый } \\
\text { ресурс, зарядов-разрядов }\end{array}$ & $2,5 \times 10^{8}$ & $2,0 \times 10^{8}$ & $2,0 \times 10^{8}$ & $2,0 \times 10^{8}$ & $9,4 \times 10^{7}$ & $9,4 \times 10^{7}$ & $6,3 \times 10^{7}$ \\
\hline $\begin{array}{l}\text { Амплитуда } \\
\text { тока, кА }\end{array}$ & \multicolumn{4}{|c|}{28} & \multicolumn{2}{|c|}{42} & 42 \\
\hline $\begin{array}{l}\text { Частота следования } \\
\text { импульсов, Гц }\end{array}$ & \multicolumn{4}{|c|}{100} & \multicolumn{2}{|c|}{10} & 10 \\
\hline
\end{tabular}

материал электродов - латунь марки Л63 ДСТУ 2060:2006, диаметр электродов - 16 мм.

Получено, что среднее значение кратковременной электрической прочности полипропиленовой пленки производства Италии $\left(E_{\text {пр ср }}+\Delta E\right)$ составляет $(653 \pm 118)$ кВ/мм, а пленки производства Украины - $(625 \pm 85)$ кВ/мм.

На основе проведенных исследований и разработанной технологии изготовления [26, 27] был создан моноблочный многофункциональный высоковольтный импульсный конденсатор. Конденсатор представляет собой размещенные в одном корпусе четыре энергозапасающих элемента, каждый рассчитывался на рабочее напряжение 3 кB с номинальной емкостью 50 мкФ. Каждый такой энергозапасающий элемент конденсатора обладает своей токовыводной системой, что позволяет изменением их электрического соединения между собой варьировать величину рабочего напряжения и номинальной емкости конденсатора. Конденсатор предназначен для работы в режиме апериодического разряда. Основные технические параметры и характеристики моноблочного многофункционального высоковольтного импульсного конденсатора приведены в табл. 4.

\section{ВЫВОДЫ}

В результате проведенного анализа были выбраны материалы рабочего диэлектрика для моноблочного многофункционального высоковольтного импульсного конденсатора, позволяющего эксплуатацию в режиме апериодического разряда с частотой следования импульсов до 100 Гц, с рабочим напряжением 3, 6 и 12 кВ, номинальной емкостью от 12 до 200 мкФ.

\section{ЛИТЕРАТУРА}

1. Шерстнев, А., Пленочные конденсаторы приходят на смену электролитическим, Электроника: Наука, Технология, Бизнес, 2006, т. 6, с. 76.

2. Ермилов, И.В., Высоковольтные импульсные конденсаторы с полимерной изоляцией, Электричество, 2006, т. 9, с. 73.

3. Шишкин, С., Юшков, А., Новое поколение косинусных конденсаторов среднего напряжения, Силовая электроника, 2007, т. 2, с. 20.

4. Гунько, В.И., Дмитришин, А.Я., Онищенко, Л.И., Топоров, С.О., и др., Исследование конструкций пленочного диэлектрика для высоковольтных импульсных конденсаторов, ЭОМ, 2012, т. 2, с. 93.

5. Баранов, М.И., Ретроспектива, современное состояние и перспективы развития исследований в области создания электроустановок с мощными накопителями электрической и магнитной энергии, Вестник НТУ «ХПИ». Серия «Электротехника и преобразовательная техника», 2004, т. 35, c. 197.

6. Кучинский, Г.С., Назаров, Н.И., Силовые электрические конденсаторы. М.: Энергоатомиздат, $1992.320 \mathrm{c}$. 
7. Гребенников, И.Ю., Гунько, В.И., Дмитришин, А.Я., Онищенко, Л.И., и др., О повышении удельных характеристик и ресурса высоковольтных импульсных конденсаторов, ЭОМ., 2004, т. 5, с. 70.

8. Ермилов, И.В., Современные импульсные конденсаторы с пленочным диэлектриком, Электронные компоненты, 2005, т. 4, с. 47.

9. Рудаков, В.В., Бойко, Н.И., Беспалов, В.Д., Высоковольтные импульсные конденсаторы разработки НИПКИ «Молния» НТУ «ХПИ», Вестник НТУ «ХПИ». Серия «Электротехника и преобразовательная техника», 2002, т. 7, с. 47.

10. Рудаков, В.В., Состояние и тенденции развития высоковольтных импульсных конденсаторов, Вестник НТУ «ХПИ». Серия « Техника и электрофизика высоких напряжений», 2009, т. 39, c. 146.

11. Гунько, В.И., Дмитришин, А.Я., Онищенко, Л.И., Топоров, С.О., и др., Разработка высоковольтных импульсных конденсаторов с пленочным диэлектриком, Вестник НТУ «ХПИ». Серия «Техника и электрофизика высоких напряжений», 2012, т. 52, с. 65.

12. Справочник по электротехническим материалам, Под ред. Ю.В. Корицкого, В 3-х т. Т. 1. М.: Энергоатомиздат, 1986. $386 \mathrm{c.}$

13. Рудаков, В.В., Кравченко, Ю.В., Ресурс пленочной полипропиленовой изоляции, пропитанной нефтяным маслом, в импульсном режиме, Вестник НТУ «ХПИ» Тем. вып.: Техника и электрофизика высоких напряжений, 2007, т. 20, с. 167.

14. Рудаков, В.В., Касаткин, В.П., Удельная энергия высоковольтных импульсных конденсаторов с лавсановым диэлектриком, Вестник НТУ «ХПИ» Тем. вып.: Техника и электрофизика высоких напряжений, 2012, т. 21, с. 233.

15. Журавлева, Н.М., Андреев, А.М., Молодова Л.А., Оптимизация состава диэлектрической системы для высоковольтных силовых металлопленочных конденсаторов. Материаль VI научнотехнического совещяания "Повышение качества $и$ улучшение технико-экономических показателей силовых конденсаторов и комплектных конденсаторных установок». Серпухов, Россия, 1991. c. 61.

16. Дмитришин, А.Я., Гунько, В.И., Онищенко, Л.И. и др., Исследование влияния повышенных температур и давления на электрическую прочность полиметилсилоксановой жидкости ПМС-20 и касторового масла, насыщенных азотом, ЭОМ., 2008, т. 3, с. 59.

17. Гребенников, И.Ю., Перекупка, И.А., Топоров, С.О. и др., Создание высоковольтного импульсного конденсатора для погружного электроразрядного комплекса, Mатериаль Международной конференциии «Физика импульсных разрядов в конденсированньх средах». Николаев, Украина, 2009. с. 142.
18. Кучинский Г.С., Галахова Л.Н., Выбор допустимых рабочих напряженностей в силовых конденсаторах с пропиткой экологически безопасными диэлектриками. Электричество. 1999, т. 1 , с. 33.

19. Андреев, А.М., Особенности разрушения синтетических пропитывающих жидкостей в высоковольтной пленочной конденсаторной изоляции, Электротехника, 2002, т. 4, с. 10.

20. Галахова, Л.Н., Павлович, А.Г., Серебренников, Н.А., Реактированные конденсаторные батареи, Mатериаль III Международной конференции «Электрическая изолящия-2002», С-Пб, Россия, 2002. с. 185.

21. Walker J., Valot A. \& ets. M/DBT, new alternative dielectric liquids for transformers. CIGRE 2012. Report D1-107.

22. Fofana I. 50 Years in the Development of Insulating Liquids. IEEE Electrical Insulation Magazine. 2013, vol. 29, no. 5, с. 13.

23. Дмитришин, А.Я., Онищенко, Л.И., Слепец, Е.Н. и др., Тенденции создания высоковольтных импульсных конденсаторов для технологий импульсной обработки различных сред, Материаль VI Международной научно-технической конференции «Перспективная техника и технологии-2010», Николаев, Украина, 2010. с. 54.

24. Журавлев, С.П., Журавлева, Н.М., Андреев, А.М., Евтич, М., Термостабильность конденсаторной полипропиленовой изоляции, Maтериальг III Международной конференции «Электрическая изоляциия-2002». С-Пб, 2002. с. 189.

25. Справочник по электротехническим материалам. Под. ред. Ю.В. Корицкого, В 3-х т., Т 2. М.: Энергоатомиздат, 1987. 467 с.

26. Гунько, В.И. Дмитришин, А.Я., Малюшевская, А.П., Танасова, Е.Д., и др., Способ изготовления высоковольтных импульсных конденсаторов с трехслойным пленочным диэлектриком. Украина пат. № 103352, 2015. Бюл. № 23.

27. Гунько, В.И., Гребенников, И.Ю., Дмитришин, А.Я., Онищенко, Л.И., и др., Способ пропитки электрических конденсаторов с пленочным диэлектриком. Украина пат. № 57999, 2011. Бюл. № 6.

\section{Summary}

The analysis of dielectric materials that can be used as working dielectric of a monoblock multifunctional highvoltage pulse capacitor is carried out. In particular, the properties of liquid dielectrics that can be used as an impregnating dielectric are considered. The properties of a polypropylene film, which is recommended for the manufacture of capacitors with a high repetition rate of charge-discharges, are also considered. Based on the analysis, recommendations are given on the use of dielectrics for the dielectric system of a monoblock multifunctional high-voltage pulse capacitor.

Keywords: film dielectric, dielectric impregnating liquid, high-voltage pulse capacitor 